\title{
A AUDIODESCRIÇÃO DE IMAGENS EM AMBIENTE VIRTUAL DE APRENDIZAGEM: PROMOVENDO A INCLUSÃO DE PESSOAS COM DEFICIÊNCIA VISUAL NA EAD
}

\author{
PORTO ALEGRE/RS MAIO/2018 \\ Deise do Amaral Tyska $\quad$ - IFRS - deisetyska@gmail.com
Lizandra Brasil Estabel $\quad$ - IFRS - lizandra.estabel@poa.ifrs.edu.br \\ Tipo: Investigação Científica (IC) \\ Natureza: Descrição de Projeto em Andamento \\ Categoria: Métodos e Tecnologias \\ Setor Educacional: EDUCAÇÃO CONTINUADA EM GERAL
}

\begin{abstract}
RESUMO
Este artigo apresenta um projeto de dissertação de mestrado com resultados parciais submetido ao programa de Pós Graduação Strictu Senso de Informática na Educação do Instituto Federal de Ciências e Tecnologias do Rio Grande do Sul (IFRS), Campus Porto Alegre. O objetivo geral do projeto é verificar como a audiodescrição, propicia às pessoas com deficiência visual (PCDV) maior autonomia e eficácia no aprendizado na modalidade de Educação Aberta a Distância (EAD) mediada por computador, no que tange à descrição de imagens. A partir das informações obtidas criou-se a ferramenta Descrimagem, na qual consiste em um repositório de imagens descritas baseadas na norma da ABNT 16452:2016. A metodologia usada foi um estudo de caso com abordagem qualitativa e de natureza aplicada realizada com os alunos de uma ONG de Porto de Alegre RS que oferece cursos livres de informática a PCDV. Os resultados obtidos até o momento permitem inferir alguns conceitos à luz da teoria de Vygotsky no que se relaciona a mediação e a zona de desenvolvimento real e proximal.
\end{abstract}

Palavras-chave: Educação a distância; audiodescrição; pessoas com deficiência 


\section{1-Introdução}

A educação aberta a distância (EAD) surge como possibilidade de qualificação para todos, devido aos progressos conquistados no que concerne as Tecnologias da Informação e Comunicação (TIC) com o amplo acesso das pessoas à internet e a esses recursos. A EAD nasceu com o propósito de atingir um grande número de pessoas e com o objetivo de facilitar o acesso ao ensino para todos em todos os níveis de educação, desde cursos livres a pós-graduações.

Nesse contexto, se faz necessário levar em consideração as questões inclusivas, estendendo essa oportunidade as pessoas com deficiência visual. Para dimensionar o número de pessoas que possuem essa deficiência, basta ter acesso aos dados do Censo Demográfico de 2010, do Instituto Brasileiro de Geografia e Estatística (IBGE) que quantificou a nível Brasil e também a nível do estado do RS o número de pessoas nessa condição.

\section{Quadro 1 - Pessoas com Deficiência Visual no Brasil e no RS}

\section{Censo Demográfico de 2010}

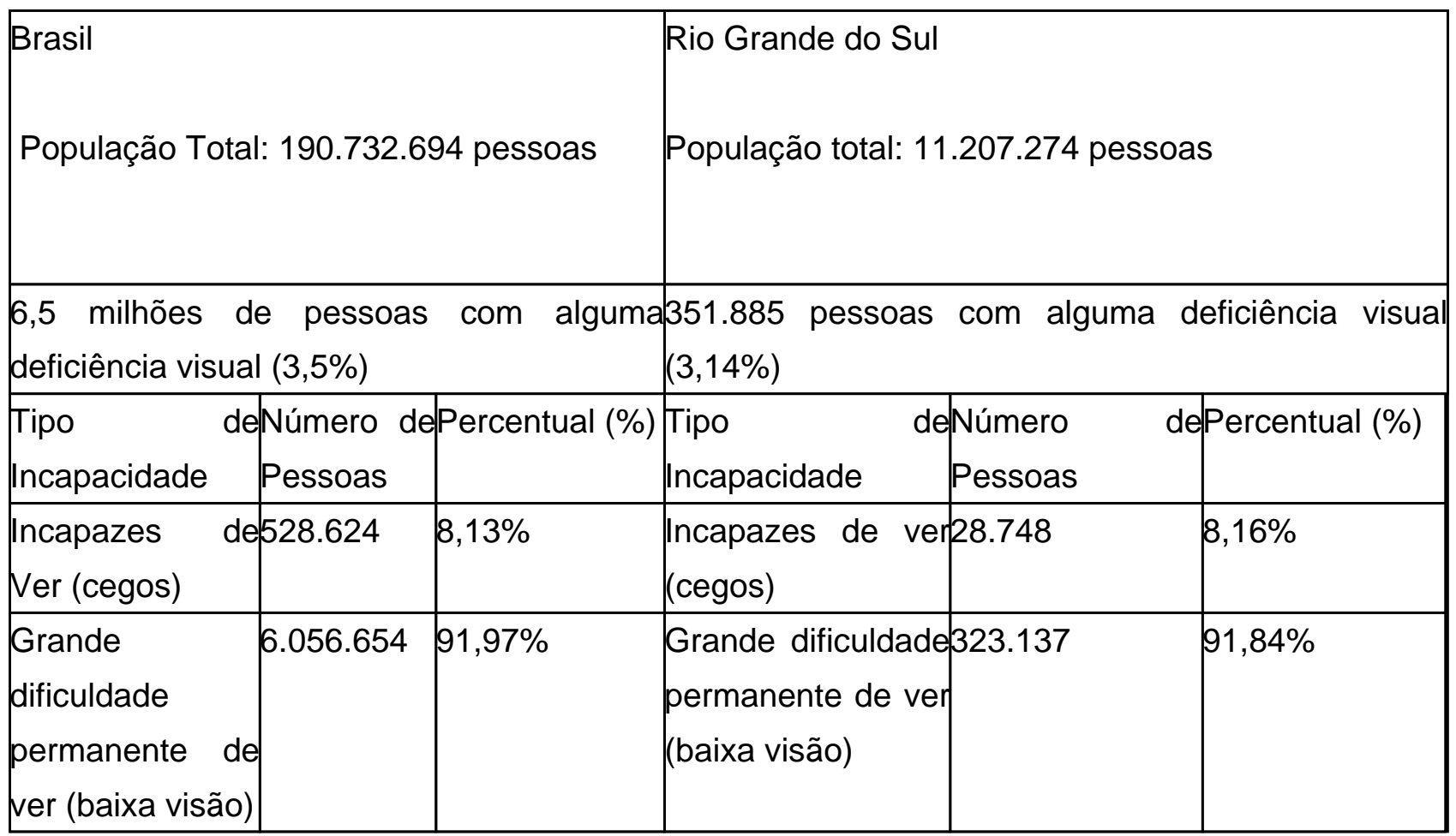

Fonte: IBGE, 2010.

Em uma sociedade onde está previsto a igualdade de direitos para todos conforme 
determina 0 artigo $5^{\circ}$ da Constituição Federal, "todos são iguais perante a lei, sem distinção de qualquer natureza [...]" (BRASIL, 1988) e que em seu art. 208 prevê que todos têm direito à educação, independente das diferenças físicas, sensoriais ou de aprendizado do aluno, é necessário que todas as pessoas, inclusive as pessoas com deficiência visual (PcDV) tenham acesso a todas as formas de ensino e que as informações disponíveis para o seu aprendizado sejam acessíveis às suas necessidades. Neste contexto, surgem as tecnologias assistivas (TA) que têm por objetivo auxiliar na inclusão destes sujeitos e dentre estas, destaca-se a audiodescrição $(A D)$, que transforma as imagens em palavras e facilita o entendimento do que é apenas visual. Com a realização da descrição os leitores de tela podem ler o que o que antes era apenas um recurso visual inacessível a estas pessoas.

É preciso entender de que forma essa inclusão, seja ela presencial ou virtual, pode acontecer e em que circunstâncias pode ser aperfeiçoado o acesso da pessoa com deficiência visual à educação nos diferentes níveis de ensino na modalidade a distância. Ademais, incluir não significa apenas matricular, é necessário assegurar que o aluno tenha acesso ao curso em sua totalidade. Pesquisar a realidade das pessoas com deficiência visual neste aspecto torna-se primordial para contribuir com o processo de inclusão destas na sociedade.

\section{2- Justificativa}

Em 2013, foi realizada pelo Senado Federal do Brasil, a segunda edição da pesquisa Condições de Vida das Pessoas com Deficiência (BRASIL, 2013), que averiguou diversos aspectos relacionados à inclusão das pessoas com deficiência na sociedade. Entre os resultados obtidos destaca-se que as pessoas com deficiência visual utilizam em sua maioria $(63,2 \%)$ a internet para se comunicar e que entre elas a área a qual acreditam que necessita de mais investimentos para uma melhor condição de vida é a educação $(30,1 \%)$, sendo que $17,6 \%$ dos entrevistados responderam que o material de ensino utilizado pelas escolas é inadequado.

A pesquisa foi realizada com 1007 pessoas, sendo que deste total $13,5 \%$ possuem deficiência visual. Comparado a primeira pesquisa realizada no ano de 2010 é notável que houve um aumento no número de pessoas com deficiência visual que utilizam a internet para se comunicar entre elas, pois em 2010 esse percentual foi de 37,65\%, nesta mesma aferição a educação alcançou 12,35\% em relação a área a qual acreditam que necessita de mais investimentos, sendo que o material didático utilizado pelas escolas foi considerado inadequado pelo mesmo percentual. Na edição de 2010 foram entrevistadas 1165 pessoas, sendo que deste total 14,6\% possuem deficiência visual. 


\section{Quadro 2 - Condições de Vida das Pessoas com Deficiência}

\begin{tabular}{|l|l|l|l|}
\hline $\begin{array}{l}\text { Condições de Vida das2010 } \\
\text { Pessoas } \\
\text { Deficiência No Brasil }\end{array}$ & 2013 & Diferença de \% \\
\hline $\begin{array}{l}\text { Número de Pessoas } 1165 \\
\text { Pesquisadas }\end{array}$ & 1007 & $-15,6 \%$ \\
\hline Com Deficiência Visual $14,6 \%$ & $13,5 \%$ & $-7,6 \%$ \\
\hline $\begin{array}{l}\text { Utilizam a internet para } 37,65 \% \\
\text { se comunicar }\end{array}$ & $63,2 \%$ & $67,8 \%$ \\
\hline $\begin{array}{l}\text { Educação necessita } 12,35 \% \\
\text { maior investimento }\end{array}$ & $30,1 \%$ & $143,7 \%$ \\
\hline $\begin{array}{l}\text { Material didático } 12,35 \% \\
\text { Necessita de maior } \\
\text { adequação }\end{array}$ & $17,65 \%$ & $42,9 \%$ \\
\hline
\end{tabular}

Fonte: Senado Federal

Estes resultados permitem perceber que houve um crescimento no uso da internet pelas pessoas com deficiência visual, bem como um aumento na importância dada para investimentos na área da educação, portanto, pode-se inferir a importância do estudo em questão, pois atentar-se para a descrição de imagens nos AVAs é uma das formas de atender algumas das necessidades apontadas nesta pesquisa.

A EAD, de acordo com o Censo da Educação Superior (CES) de 2016, continua em ascendência no Brasil, atingindo 1,5 milhão de matrículas em 2016, o que representa uma participação de $18,6 \%$ do total de matrículas da Educação Superior. Comparado com os números de ingresso em 2015 nos cursos a distância este número cresceu $7,2 \%$, já nos cursos presenciais houve uma redução no número de ingresso de 1,2\%, 0 que denota a expansão da oferta de cursos a distância. Vale ressaltar que a educação a distância em 2006 representava apenas 4,2\% das matrículas no ensino superior, e até 2016 havia crescido $330 \%$ neste indicador.

Através da EAD é possível fazer com que PcDV ampliem o seu contato com o mundo e consequentemente interajam com os videntes. A EAD propicia a inclusão de diferentes maneiras, pois permite que pessoas dos mais variados lugares tenham acesso à educação, podendo estudar no local em que desejarem e nos horários que forem convenientes. Para isto, os AVAs direcionados à educação devem ter a responsabilidade de considerar as características e necessidades de seus usuários, pois 
devem oferecer suporte ao desenvolvimento das capacidades e servir de motivação para o aprendizado dos educandos. A iniciativa de aprofundar os estudos para promover a inclusão das PcDV de forma mais adequada ao ensino ofertado pela EAD poderá contribuir para que estes se sintam cidadãos mais respeitados em seus direitos, integrantes da sociedade da informação e empoderados para ter uma melhor qualificação e posicionamento no mercado profissional.

Além disto, é importante que a comunidade científica comece a perceber as necessidades dessa fatia da sociedade para poder mostrar que a tecnologia é um mecanismo de inclusão para todos. Neste sentido, reside a importância social deste estudo, na medida em que trará ideias sobre a possibilidade de tornar mais satisfatória e autônoma a EAD quando da utilização dos AVAs existentes.

\section{3- Objetivos}

\section{1 - Objetivo geral}

Verificar como a audiodescrição propicia às pessoas com deficiência visual maior autonomia e eficácia no aprendizado na modalidade EAD mediada por computador, no que tange à descrição de imagens.

\section{2 - Objetivos específicos}

1. Identificar quais são as maiores dificuldades do aluno com deficiência visual (DV) no acesso às TIC para entender as imagens dispostas no AVA Moodle.

2. Observar de que forma o uso da TA de AD poderá auxiliar a entender as imagens neste ambiente virtual.

3. Desenvolver uma ferramenta, Descrimagem, para inclusão de imagens descritas, as quais possam ser utilizadas em AVAs.

4. Analisar os resultados encontrados após a aplicação da pesquisa.

\section{4- Fundamentação Teórica:}

A EAD é uma modalidade de ensino que permite que pessoas dos mais variados lugares tenham acesso à Educação, podendo estudar no local em que desejarem e no horário que for conveniente. Ela é mediada por diferentes formas de interação que facilitam a transposição de barreiras físicas e temporais.

No Brasil a EAD está prevista no decreto Lei Federal no 5.622, de 19 de dezembro de 
2005, o qual a caracteriza como: (...) modalidade educacional na qual a mediação didático pedagógica nos processos de ensino e aprendizagem ocorre com a utilização de meios e tecnologias de informação e comunicação (TIC), com estudantes e professores desenvolvendo atividades educativas em lugares ou tempos diversos.

A audiodescrição (AD) é uma TA que transforma aquilo que não é visto em palavras. Sendo assim, tem o objetivo de auxiliar as pessoas com deficiência visual a compreender o mundo, extremamente visual contribuindo assim para o processo de inclusão. Para Motta e Romeu Filho (2010) a AD é um recurso de acessibilidade que melhora a compreensão das pessoas com deficiência visual em diversos eventos culturais, tanto gravados como ao vivo, como programas de televisão, exposições, espetáculos teatrais, seminários, congressos entre outros, mediante a informação sonora.

Em termos de normatização, a Associação Brasileira de Normas Técnicas (ABNT) elaborou a Norma Brasileira (NBR) 16452:2016 publicada em 01 de Setembro de 2016. Esta norma tem o intuito de normalizar a produção da audiodescrição para garantir a qualidade da acessibilidade aos serviços e produtos audiovisuais e atender às necessidades das pessoas com alguma deficiência, principalmente cognitiva ou visual, com equidade de direitos. $O$ recurso da $A D$ beneficia não somente pessoas com deficiência visual, mas também pessoas com dislexia, deficiência intelectual e idosos.

O uso de uma tecnologia assistiva para apoio ao aprendizado de pessoas com deficiência, neste estudo a AD de imagens para pessoas com deficiência visual, requer uma sólida teoria científica que valide a pesquisa. Nesta investigação optou-se pelo uso da teoria sócio-histórica de Vygotsky que trabalhou com uma relação dialética, entre o ambiente sociocultural e o processo de transformação e evolução da cultura.

A mediação é um conceito primordial para o entendimento do fundamento sócio histórico do funcionamento psicológico, a relação do homem com o mundo não é uma relação direta e sim mediada pelos instrumentos e signos. Para Rego (2000) a relação indivíduo-sociedade e as características especificamente humanas resultam da interação dialética entre homem e seu meio sócio cultural. Simultaneamente, o ser humano ao transformar o meio para atender as suas necessidades básicas, transformase a si mesmo. A mediação é o que caracteriza a relação do homem com o mundo e com outros sujeitos, e compreender esta questão é essencial, pois é deste modo que as funções psicológicas superiores, inerentemente humanas, se desenvolvem. O desenvolvimento e aprendizagem estão inter-relacionados e se baseiam na relação do sujeito com seu ambiente físico e social, segundo uma relação dialética (Vygotsky, 
2010).

Vygotsky (1998) com seu abrangente olhar sobre os processos de interação social sugeriu os mecanismos pelos quais a cultura torna-se parte componente da natureza de cada ser humano. É importante salientar que de acordo com Rego (2000) a cultura para Vygotsky não é algo pronto e estático, e sim algo que está sempre em constante movimentação e recriação com reinterpretações de informações, conceitos e significados. Para Vygotsky a relação do homem com o mundo não é uma relação direta e sim mediada. Dessa forma, Vygotsky distinguiu dois elementos básicos incumbidos por essa mediação: o instrumento e o signo. O instrumento que é o mediador entre os indivíduos e os objetos e o signo que corresponde a dispositivos da atividade psicológica e que regula as ações sobre o psiquismo das pessoas. O signo age como um instrumento da atividade psicológica de maneira análoga ao papel de um instrumento no trabalho (Vygotsky, 2007, p.52).

Para Oliveira (1997) a mediação é o processo de intervenção de um elemento intermediário numa relação, a relação deixa de ser direta e passa a ser mediada por este elemento. Portanto, a ideia de mediação é a ideia de intermediação, uma coisa interposta entre uma coisa e outra. Oliveira (1997, p.33) ainda complementa a ideia de mediação afirmando que: o processo de mediação, por meio de instrumentos e signos, é fundamental para o desenvolvimento das funções psicológicas superiores, distinguindo o homem dos outros animais. A mediação é um processo essencial para tornar possível as atividades psicológicas voluntárias, intencionais, controladas pelo próprio indivíduo.

Pode-se dizer que a analogia básica entre signo e instrumento reside na função mediadora que os caracteriza. Logo, eles podem ser representados conforme a figura abaixo:

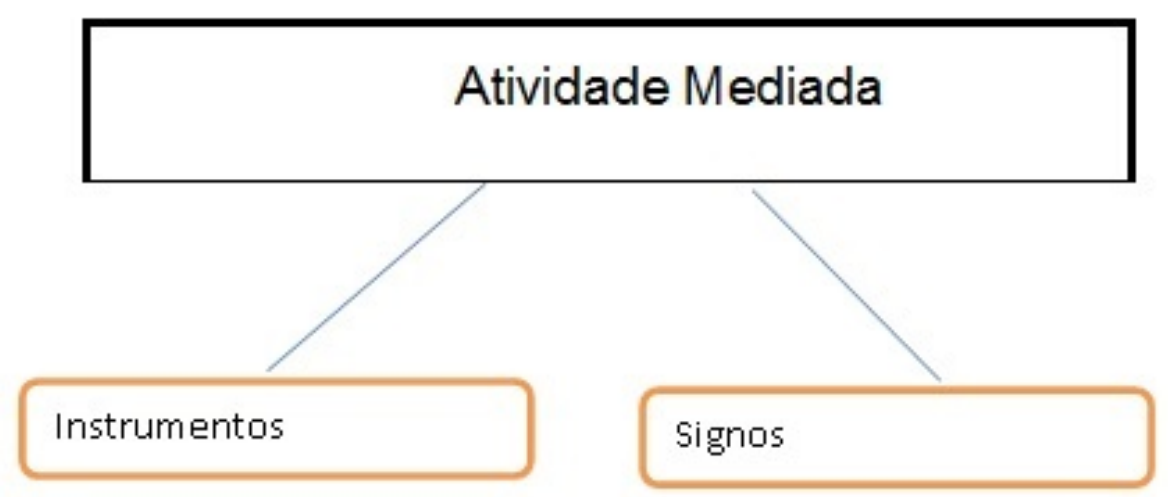




\section{5 -Metodologia}

A pesquisa trabalhou com um estudo de caso de abordagem qualitativa de natureza aplicada. Os sujeitos participantes desta pesquisa são alunos da ONG Rumo Norte localizada na cidade de Porto Alegre - RS do curso livre em informática. Alguns alunos possuem cegueira total e outros baixa visão. Realizou-se a observação direta e a entrevista semiestruturada em dois encontros presenciais. Além disso, se analisará as respostas dadas às questões dispostas no curso: Audiodescrição de imagens para pessoas com deficiência visual realizadas posteriormente de forma virtual pelo AVA Moodle.

\section{6 - Resultados Parciais}

Vive-se em uma sociedade absorta por uma cultura imagética, cheia de multiplicidades visuais que nos envolve por seu dinamismo. Entretanto, na prática, sabe-se que muitos indivíduos com deficiência visual deixam de relacionar-se com algumas atividades, como por exemplo, as de cunho culturais, como frequentar cinemas, teatros, museus, por não serem atendidos quanto à acessibilidade visual. No entanto, essa situação também ocorre quanto às práticas educacionais, como pode-se verificar no acesso à ambientes virtuais de aprendizados,

Nota-se a condição mediadora da audiodescrição de imagens nos depoimentos dos sujeitos participantes da pesquisa quando questionados se com a descrição perceberam alguma diferença em relação à imagem, conforme abaixo:

Me deu noção do que está acontecendo na imagem, eu consigo imaginar o que está ali. (Sujeito 3)

Me ajuda a criar outras referências no imaginário, eu saio do ver para o algo que é mais sensação. (Sujeito 2)

Observou-se a presença do uso de signos quando, no segundo encontro presencial, se realizou a indagação se o entendimento do texto seria diferente se não houvesse a descrição de imagens, conforme trecho abaixo:

(...) se recorda do tempo da radionovela ouvindo a descrição, pois cada um tinha sua preferida e ouvia e imaginava as cenas, como os barulhos de trovão e relâmpago que eram feitos com chapas de raio $x$ e assim com a audiodescrição acontece a mesma coisa. (Sujeito 2) 
Foi possível perceber a importância da descrição das imagens na educação a distância no segundo encontro presencial na aplicação da pesquisa, quando foram apresentados quatro textos distintos complementados com imagens descritas. No momento do estudo do texto três, intitulado o primeiro beijo, os sujeitos ouviram com o auxílio do leitor de tela NVDA o texto. Quando questionados se de acordo com o texto o rapaz nunca beijou antes as respostas foram as seguintes:

o rapaz demora para responder mas diz não sem convicção, acho que ele possa não se lembrar se já beijou antes. (Sujeito 3)

ele murmurou e disse não (Sujeito 5)

ele hesitou na resposta, pode ser que esteja mentindo. (Sujeito 1)

Após as respostas os sujeitos ouvem novamente o texto e na sequência a descrição da imagem. Quando perguntados se de acordo com o texto e a imagem a namorada acreditou na resposta do rapaz, as afirmações foram as seguintes:

não (sujeito 4)

ela ficou em dúvida (Sujeito 3)

acho que não (Sujeito 1)

Em seguida são indagados se não houvesse a imagem descrita apenas o texto vocês diriam que a namorada acreditou na resposta dada pelo rapaz. As declarações foram as seguintes:

se não houvesse a descrição da figura não teria como entender isso.(Sujeito 4)

se não houvesse a imagem não haveria dúvida quanto a resposta do rapaz. (Sujeito 2)

dá para perceber que ela ficou pensativa pois colocou a mão direita na cabeça e a esquerda na cintura e ainda apareceram três pontos de interrogação. (Sujeito 1)

Nesta situação a audiodescrição foi usada como um instrumento para atender as necessidades específicas destes sujeitos para que estes pudessem compreender o texto e sua mensagem complementar transmitida pelo elemento visual. 


\section{Considerações Finais}

De acordo com as primeiras informações coletadas percebe-se que a ferramenta assistiva da audiodescrição pode ser utilizada como mediadora no processo de compreensão das pessoas com deficiência visual quando do acesso à imagens dentro de ambientes virtuais de aprendizagem. Dessa forma se faz necessário aprofundar os estudos realizando novos encontros presenciais e a efetivação do curso de forma virtual em suas residências para verificar as dificuldades encontradas pelos sujeitos e o quanto a descrição, através do uso da ferramenta Descrimagem possibilitou na realização das atividades propostas.

\section{Referências}

BRASIL. Constituição Federal. Art. 208, Brasília-DF, 1988.

BRASIL. Decreto № 5.622, de 19 de dezembro de 2005. Disponível em:http://www.planalto.gov.br/ccivil_03/_ato2004-2006/2005/decreto/d5622.htm Acesso em 20 abr. 2016.

MOTTA, Lívia M. V. de M., FILHO, Paulo R.(org.) Audiodescrição: transformando imagens em palavras. São Paulo: Secretaria dos Direitos da Pessoa com Deficiência do Estado de São Paulo, 2010.

OLIVEIRA, Marta Kohl. Vygotsky: Aprendizado e Desenvolvimento: um processo sócio-histórico. São Paulo: Scipione, 1997.

REGO, Teresa Cristina. Vygotsky: uma perspectiva histórico-cultural da educação. 10ed. Petrópolis: Vozes, 2000.

VYGOTSKI, Lev. S. Obras Escogidas: fundamentos de defectologia. v.5. Madrid: Visor, 1997.

VYGOTSKI, Lev. S. Pensamento e Linguagem. 6. ed. São Paulo: Martins Fontes, 1998.

VYGOTSKY, LEV S. A formação Social da Mente: o desenvolvimento dos processos psicológicos superiores. 3.ed. São Paulo: Martins Fontes, 2007 